\title{
Application of Renewal Gray GM $(1,1)$ Model to Prediction of Landslide Deformation
}

\author{
Zhaoyang Wang \\ College of Geology \& Environment, Xi'an University of Science and Technology, Xi'an, China \\ Email: wangzhaoyang1999@126.com
}

How to cite this paper: Wang, Z.Y. (2017) Application of Renewal Gray GM $(1,1)$ Model to Prediction of Landslide Deformation. Journal of Geoscience and Environment Protection, 5, 148-154.

https://doi.org/10.4236/gep.2017.59011

Received: August 7, 2017

Accepted: September 8, 2017

Published: September 11, 2017

Copyright $\odot 2017$ by author and Scientific Research Publishing Inc. This work is licensed under the Creative Commons Attribution International License (CC BY 4.0).

http://creativecommons.org/licenses/by/4.0/

\begin{abstract}
The gray renewal GM $(1,1)$ landslide prediction model was established by improving the gray model. Based on the established model, the author has made prediction of landslide deformation to the Xiangjiapo landslide and the Lianziya dangerous rock body. The results show that the gray renewal GM $(1,1)$ model can supplement the new information in time and remove the old information which reduces the meaning of the information because of time lapse. Therefore, the model is closer to reality.
\end{abstract}

\section{Keywords}

Landslide, Renewal Gray GM $(1,1)$ Model, Gray System Theory

\section{Introduction}

Landslide prediction research has started from the 1960s, and has now become a hot topic in landslide research. Due to the complexity of the landslide problem, landslide time prediction is still a worldwide problem. In these recent years, domestic and foreign experts and scholars in the landslide forecast theoretical research and practical work in the geotechnical engineering field have done a lot of work, and achieved remarkable results [1] [2] [3] [4] [5], for disaster prevention and mitigation played a role. But many studies are still in the exploratory research phase.

There are many ways to forecast landslides, although the methods have their own unique, but there are corresponding shortcomings and deficiencies. The gray system analysis method has a good applicability for the incomplete or incomplete information. The GM $(1,1)$ model has been widely used in landslide prediction [6] [7] [8]. In this paper, renewal gray GM $(1,1)$ model is used to forecast the landslide, and the prediction accuracy is obviously improved. Renewal gray GM $(1,1)$ model is superior to the GM $(1,1)$ prediction model by the model accuracy test. 


\section{Gray System Theory}

\subsection{The Basic Idea of Gray System Prediction}

Gray system theory is a famous scholar founded by professor Deng J. L. in 1982. It is based on the small sample of "some information is known and some information is unknown", and the "poor information" uncertainty system is the main research object. "Part" known information generation, development, extraction of valuable information, to achieve the correct understanding of the system and the exact description of the law, and scientific forecasting. Gray system is through the finishing of the original data to seek its changing laws, while the future state of the system to make scientific predictions. The gray prediction model, also known as the GM model, can be used to observe, analyze and long-term predictions of the studied system.

\subsection{Conventional Gray GM $(1,1)$ Model Principle [9] [10]}

Assuming that the original number as $X^{(0)}$

$$
X^{(0)}=\left(x^{(0)}(1), x^{(0)}(2), \cdots, x^{(0)}(n)\right)
$$

According to the gray system theory on the original sequence of first-order accumulation (1-AGO) generated, the resulting column is:

$$
X^{(1)}=\left(x^{(1)}(1), x^{(1)}(2), \cdots, x^{(1)}(n)\right)
$$

$x^{(1)}(k)$ can be calculated using the following formula:

$$
x^{(1)}(k)=\sum_{i=1}^{k} x^{(0)}(i), k=1,2, \cdots, n
$$

The differential equation of the albino form of the system prediction model GM $(1,1)$ is expressed as:

$$
\frac{\mathrm{d} x^{(1)}}{\mathrm{d} t}+a x^{(1)}=b
$$

Assuming that $\hat{a}=|a, b|^{\mathrm{T}}$, then identification $a$ can be calculated by the following formula

$$
\begin{gathered}
\text { where } Y=\left[\begin{array}{c}
x^{(0)}(2) \\
x^{(0)}(3) \\
\vdots \\
x^{(0)}(n)
\end{array}\right] \\
\qquad \hat{a}=|a, b|^{\mathrm{T}}=\left(B^{\mathrm{T}} B\right)^{-1} B^{\mathrm{T}} Y
\end{gathered}
$$


Then the time response sequence can be expressed as

$$
\hat{x}^{(1)}(k+1)=\left(x^{(0)}(1)-\frac{b}{a}\right) \mathrm{e}^{-a k}+\frac{b}{a}, k=1,2, \cdots, n
$$

The simulation value is expressed as

$$
\hat{x}^{(0)}(k+1)=\hat{x}^{(1)}(k+1)-\hat{x}^{(1)}(k), k=1,2, \cdots, n
$$

\subsection{Gray Metabolism GM $(1,1)$ Model Principle}

In the conventional GM $(1,1)$ model modeling, the past data from the real time $t=n$ is used. However, the development of any gray system, with the passage of time, will continue to have some random disturbance factors into the system, so that the development of the system affected. Therefore, with the conventional GM $(1,1)$ model, the higher accuracy is only a few recent data, farther away from reality, the weaker the prediction. In order to reflect the impact of the future random disturbance on the gray system and improve the prediction accuracy, the GM $(1,1)$ model is grayed out.

In the original data $X^{(0)}=\left(x^{(0)}(1), x^{(0)}(2), \cdots, x^{(0)}(n)\right)$, the latest information $x^{(0)}(n+1)$ is placed and the oldest information $x^{(0)}(1)$, $X^{(0)}=\left(x^{(0)}(2), x^{(0)}(3), x^{(0)}(n+1)\right)$ is removed. The model established according to the above steps is the gray metabolic GM $(1,1)$ model, and a series of prediction data is obtained at the same time.

\subsection{Accuracy Test}

The accuracy of the gray prediction model is usually checked by the posterior difference method. The model accuracy is evaluated by the mean square error ratio and the small error probability. The smaller the mean square error ratio and the smaller the probability of small errors, the higher the accuracy of the prediction model. The basic method is as follows: assuming $X^{(0)}$ for the original sequence, $\hat{x}^{(0)}$ for the GM $(1,1)$ model simulation sequence, $\varepsilon^{(0)}$ for the residual series, then

$$
\begin{gathered}
\bar{x}=\frac{1}{n} \sum_{k=1}^{n} x^{(0)}(k), \\
S_{1}^{2}=\frac{1}{n} \sum_{k=1}^{n}\left(x^{(0)}(k)-\bar{x}\right)^{2}
\end{gathered}
$$

Respectively, the mean of $X^{(0)}$, variance;

$$
\begin{gathered}
\varepsilon^{(0)}(k)=x^{(0)}(k)-\hat{x}^{(0)}(k) \\
\bar{\varepsilon}=\frac{1}{n} \sum_{k=1}^{n}\left(\varepsilon^{(0)}(k)-\bar{\varepsilon}\right)^{2} \\
S_{2}^{2}=\frac{1}{n} \sum_{k=1}^{n}\left(\varepsilon^{(0)}(k)-\bar{\varepsilon}\right)^{2} \\
C=\frac{S_{2}}{S_{1}}
\end{gathered}
$$


where $\bar{\varepsilon}$ is the mean of residual $\varepsilon^{(0)}(k), S_{2}^{2}$ is the residual variance, and $C$ is the mean square deviation. The mean square error ratio $C$ and the small error probability $p$ are calculated from $C=\frac{S_{2}}{S_{1}}$ and $p=P\left(|\varepsilon(k)-\bar{\varepsilon}|<0.6745 S_{1}\right)$.

The accuracy of the model is shown in Table 1.

\section{Model Application Example}

\subsection{Xiangjiapo Landslide}

In order to test the actual prediction effect of the gray metabolic prediction model, Xiangiiapo landslide data were used to predict. The landslide is located in K13+500 - K13+960 of Chongqing-Guizhou expressway. The landslides in the landslide are the quaternary of the quaternary system and the Jurassic lower Pearl Group $\left(\mathrm{J}_{1 \mathrm{Z}}\right)$, the spontaneous flow $\left(\mathrm{J}_{1-2 \mathrm{Z}}\right)$ and the Triassic upper Xujiahe formation $\left(\mathrm{T}_{3 \mathrm{X}}\right)$. The landslide occurred mainly in the quaternary landslide accumulation layer $\left(\mathrm{Q}_{4}^{\mathrm{del}}\right)$ and the quaternary system $\left(\mathrm{Q}_{4}^{\mathrm{col}+\mathrm{dl}}\right)$. The landslide is mainly composed of silty clay clumps and strong weathering sand and mudstone. It belongs to mixed rock and rock landslide. The rock mass structure is loose, the water content is high, unstable and easy to deform.

The highway landslide monitoring information see the literature [11], displacement measured in Table 2. According to the data, it can be seen that the time series of landslide deformation has obvious increasing trend and obvious nonlinearity. Therefore, the renewal GM $(1,1)$ model can be used to predict the displacement of JB5. The prediction results are shown in Table 3. The accuracy of the model is shown in Table 4.

Model 1 is the predicted value using $t=1,2,3,4,5$, and 6 weeks. Model 2 is the predicted value using $t=2,3,4,5,6$ and 7 weeks. Model 3 is the predicted value using $t=3,4,5,6,7$, and 8 weeks. As can be seen from Table 3, $t=9$ weeks of the relative error from $32.89977 \%$ gradually reduced to $6.126906 \%$. It can be seen from Table 4 that the accuracy of model 1 is two, and the accuracy

Table 1. The reference table of precision check grade.

\begin{tabular}{|c|c|c|}
\hline Model accuracy level & Small probability of error $p$ & Mean square deviation ratio \\
\hline Level 1 (good) & $\geq 0.95$ & $\leq 0.35$ \\
\hline Level 2 (qualified) & $0.80 \ll p<0.95$ & $0.35<C \leq 0.50$ \\
\hline Level 3 (barely) & $0.70 \ll p<0.80$ & $0.50<C \leq 0.65$ \\
\hline Level 4 (unqualified) & $<0.70$ & $>0.65$ \\
\hline
\end{tabular}

Table 2. Actual displacements of No. JB5 monitoring point in Xiangjiapo.

\begin{tabular}{lccccccccc}
\hline Monitoring date & 1 & 2 & 3 & 4 & 5 & 6 & 7 & 8 & 9 \\
\hline $\begin{array}{c}\text { Measuring } \\
\text { point } \\
\begin{array}{c}\text { displacement } \\
\text { value/mm }\end{array}\end{array}$ & 32.300 & 48.600 & 69.600 & 96.370 & 128.700 & 168.200 & 207.870 & 256.400 & 306.800 \\
\hline
\end{tabular}


Table 3. The forecast data and relative error of information renewal GM $(1,1)$.

\begin{tabular}{cccccccc}
\hline $\begin{array}{c}\text { Observed } \\
\text { total time/ } \\
\text { week }\end{array}$ & $\begin{array}{c}\text { Measured } \\
\text { value/mm }\end{array}$ & Model 1 & $\begin{array}{c}\text { Relative } \\
\text { error/\% }\end{array}$ & Model 2 & $\begin{array}{c}\text { Relative } \\
\text { error/\% }\end{array}$ & Model 2 & $\begin{array}{c}\text { Relative } \\
\text { error/\% }\end{array}$ \\
\hline 1 & 32.300 & 32.30000 & 0 & & & & \\
2 & 48.600 & 51.70845 & 6.39598 & 48.6 & 0 & & \\
3 & 69.600 & 69.45098 & 0.21411 & 74.3689 & 6.85182 & 69.6 & 0 \\
4 & 96.370 & 93.28144 & 3.20490 & 96.4319 & 0.06426 & 101.6628 & 5.49217 \\
5 & 128.700 & 125.28876 & 2.65054 & 125.0405 & 2.84346 & 128.3116 & 0.30181 \\
6 & 168.200 & 168.27863 & 0.04675 & 162.1363 & 3.60505 & 161.9458 & 3.71833 \\
7 & 207.870 & 226.01947 & 8.73116 & 210.2374 & 1.13889 & 204.3965 & 1.67102 \\
8 & 256.400 & 303.57270 & 18.39809 & 272.6087 & 6.32164 & 257.9747 & 0.61416 \\
9 & 306.800 & 407.73650 & 32.89977 & 353.4837 & 15.21633 & 325.5973 & 6.12691 \\
\hline
\end{tabular}

Table 4. Data table of precision check grade.

\begin{tabular}{|c|c|c|c|}
\hline model & Relative error $\alpha$ & $\begin{array}{c}\text { Mean square deviation } \\
\text { ratio } C\end{array}$ & $\begin{array}{l}\text { Small probability of error } \\
p\end{array}$ \\
\hline model 1 & 0.09068 & 0.38085 & 1 \\
\hline model 2 & 0.05149 & 0.19714 & 1 \\
\hline model 3 & 0.02987 & 0.10169 & 1 \\
\hline
\end{tabular}

of model 3 is level 1, and the values of $C$ and $\alpha$ are decreasing from model 1 to model 3, indicating that the accuracy of the model is gradually increasing. It can be seen that the gray renewal GM $(1,1)$ model is used to predict, because the system constantly update the modeling data, remove the old data, so that the system's prediction accuracy has been improved, gradually close to the measured value.

\subsection{Lianziya Hazardous Rock Masses}

The rock masses is located in the south bank of the Xiling gorge in the Xintan Town, Zigui Town, Zigui County, Hubei Province. It is located at $26 \mathrm{~km}$ from the Sandouping dam. The site and the new beach landslide confrontation, its length $700 \mathrm{~m}$, east-west width of $30-200 \mathrm{~m}$, nearly $100 \mathrm{~m}$ high. According to the monitoring data of the Lianziya hazardous rock masses in the literature [12] from december 1978 to december 1985, the monitoring data were predicted. Gray renewal GM $(1,1)$ model for GA monitoring point displacement change prediction results in Table 5.

Model 1 is the predicted value when the observed values are from 1978.12 to 1983.12, the model 2 is the predicted value at 1979.12 to 1984.12 , and the model 3 is the predicted value at 1980.12 to 1985.12 . As can be seen from Table 6, the values of the model accuracy test values $C$ and $\alpha$ are decreasing from model 1 to model 3, indicating that the accuracy of the model is increasing. From the prediction results, it can be seen that the gray renewal GM $(1,1)$ model not only 
Table 5. The simulation-forecast results of renewal GM $(1,1)$ model in Lian Ziya hazardous rock masses $\left(\mathrm{G}_{\mathrm{A}}\right)$.

\begin{tabular}{cccccccc}
\hline $\begin{array}{c}\text { Time } \\
\text { (year/ } \\
\text { month) }\end{array}$ & $\begin{array}{c}\text { Displacement } \\
\text { observations/ } \\
\text { mm }\end{array}$ & model 1 & $\begin{array}{c}\text { Relative } \\
\text { error/\% }\end{array}$ & model 2 & $\begin{array}{c}\text { Relative } \\
\text { error/\% }\end{array}$ & model 3 & $\begin{array}{c}\text { Relative } \\
\text { error/\% }\end{array}$ \\
\hline 1978.12 & 10.32 & 10.32 & 0 & & & & \\
1979.12 & 26.96 & 29.37167 & 8.94537 & 26.96 & 0 & & 0 \\
1980.12 & 34.07 & 32.97365 & 3.21794 & 35.43405 & 4.00365 & 34.07 & 3.17901 \\
1981.12 & 38.65 & 37.01735 & 4.22420 & 38.25624 & 1.01879 & 39.87869 & 2.21771 \\
1982.12 & 42.98 & 41.55695 & 3.31097 & 41.30320 & 3.90134 & 42.02683 & 2.42292 \\
1983.12 & 44.93 & 46.65325 & 3.83542 & 44.59285 & 0.75038 & 44.29068 & 1.4225 \\
1984.12 & 47.16 & 52.37454 & 11.05713 & 48.14451 & 2.08759 & 46.67648 & 1.02527 \\
1985.12 & 48.38 & 58.79746 & 21.53258 & 51.97904 & 7.43911 & 49.19080 & 1.67590 \\
\hline
\end{tabular}

Table 6. Data table of precision check grade.

\begin{tabular}{cccc}
\hline \multirow{2}{*}{ model } & Relative error $\alpha$ & $\begin{array}{c}\text { Mean square deviation } \\
\text { ratio } C\end{array}$ & Small probability of error \\
model 1 & 0.08018 & 0.33823 & 0.857 \\
model 2 & 0.03200 & 0.23306 & 1 \\
model 3 & 0.01904 & 0.17360 & 1 \\
\hline
\end{tabular}

has high prediction accuracy, but also has strong self-adjustment ability. It can adjust the model parameters with the new data, and reflect the evolution direction of the system in time prediction.

\section{Conclusion}

Based on the data of GA point deformation data of Xiangjiapo landslide and Lianziya hazardous rock masses, this paper uses the gray renewal GM $(1,1)$ model method to predict the landslide. The results show that the gray metabolic GM $(1,1)$ model can supplement the new information in time and remove the old information which reduces the meaning of the information because of time lapse. Therefore, it can reflect the current characteristics of the system. The model is closer to reality. The method has high accuracy, the prediction results can be used to guide the construction site, to achieve the dynamic management of landslide management, and application prospects are very broad.

\section{References}

[1] Li, X.F., Wei, Y.X. and Yang, H.M. (2013) Time Forecast for Huangci Landslide by Back Analysis. Journal of Wuhan Institute of Technology, 35, 52-54. https://doi.org/10.1007/s11595-013-0639-Z

[2] Xu, Q., Huang, R.Q. and Li, X.Z. (2004) Research Progress in Time Forecast and Prediction of Landslides. Advance in Earth Sciences, 19, 478-483.

[3] Tan, W.P., Zheng, Y.R. and Chen, W.B. (2010) Studies on the Land-Slope Forecast and Early Warning by More Means in Full Dynamic Discourse. Sichuan Building 
Science, 36, 106-111.

[4] Zhuo, Y., He, Z.W., Zhao, Y.B., et al. (2014) Monomer Warning System Realization Based on an Improved Landslide Prediction Model of Tangent Angle Monomer. Science of Surveying and Mapping, 39, 73-75.

[5] Zhou, Y., Liu, Z.P., Sheng, Z.J. and Zhang, G.P. (2016) Rainfall-Induced Landslide of Yingxia Railway Forecasting and Warning Models Based on Effective Precipitation. The Chinese Journal of Geological Hazard and Control, 27, 22-25.

[6] Wang, D., Huang, X., Wang, M.D. and Liu, T.B. (2013) Application of Gray $\mathrm{GM}(2,1)$ Model to Prediction of Landslide Deformation. Hydrogeology \& Engineering Geology, 40, 52-54.

[7] Li, X.Z., Kong, J.M. and Wang, C.H. (2007) Application of Center Approach Grey GM(1,1) Model to Prediction of Landslide Deformation with a Case Study. Journal of Engineering Geology, 15, 673-676.

[8] Xiao, Y. and Li, X.F. (2012) Forecast for Landslide Based on Optimum Grey Model. Journal of Wuhan Institute of Technology, 34, 31-35.

[9] Deng, J.L. (1987) Gray System Basic Method. Huazhong University of Science \&Technology Press, Wuhan, 104-108.

[10] Liu, S.F. and Guo, T.B. (1991) Grey System Theory and Application. Henan University Press, Kaifeng, 150-163.

[11] Yin, G.Z., Zhang, W.Z., Zhang, D.M., et al. (2007) Forecasting of Landslide Displacement Based on Exponential Smoothing and Nonlinear Regression Analysis. Rock and Soil Mechanics, 28, 1725-1728.

[12] Li, T.B., Chen, M.D. and Wang, L.S. (1999) Landslide Real-Time Tracking and Prediction. Chengdu University of Science and Technology Press, Chengdu, 27-31.

Scientific Research Publishing

Submit or recommend next manuscript to SCIRP and we will provide best service for you:

Accepting pre-submission inquiries through Email, Facebook, LinkedIn, Twitter, etc. A wide selection of journals (inclusive of 9 subjects, more than 200 journals)

Providing 24-hour high-quality service

User-friendly online submission system

Fair and swift peer-review system

Efficient typesetting and proofreading procedure

Display of the result of downloads and visits, as well as the number of cited articles

Maximum dissemination of your research work

Submit your manuscript at: http://papersubmission.scirp.org/

Or contact gep@scirp.org 